\title{
CDISC SDTM Model Version 1.2
}

National Cancer Institute

\section{Source}

National Cancer Institute. CDISC SDTM Model Version 1.2. NCI Thesaurus. Code C161426.

The 1.2 version of the CDISC Study Data Tabulation Model (SDT M). 